\title{
Política de PERMANÊNCIA E ÊXITO NA EDUCAÇÁO SUPERIOR: PERSPECTIVAS DOCENTES SOBRE A REPROVAÇÁO ESCOLAR
}

\author{
Policy OF PERMANENCE AND SUCCESS IN THE HIGHER \\ EDUCATION: TEACHERS PERSPECTIVES ABOUT FAILURE
}

\author{
Simone Braz Ferreira Gontijo \\ Doutora em Educação pela Universidade de Brasília. Professora do Instituto Federal de Brasília. \\ Brasília - DF - Brasil. \\ ORCID: http://orcid.org/0000-0002-8245-3841 \\ simonegonti@gmail.com
}

Mariana Rocha Fortunato

Graduada em Letras Espanhol pelo Instituto Federal de Brasília.

Brasília - DF - Brasil.

ORCID: http://orcid.org/0000-0003-2133-9663

marirochafortunato@gmail.com

Juliana Harumi Chinatti Yamanaka

Mestre em Linguística Aplicada pela Universidade de Brasília. Professora do Instituto Federal de Brasília.

Brasília - DF - Brasil.

ORCID: http://orcid.org/0000-0001-5783-5939

julianalapsis@gmail.com

Resumo: A reprovaçáo na educação superior constitui o objeto de pesquisa deste artigo. Partiu-se do princípio de que a percepçáo docente sobre a reprovaçáo influencia a intencionalidade da ação pedagógica e as políticas de permanência e êxito dos estudantes. A investigação valeu-se do modelo quanti-qualitativo para coleta, organizaçáo e análise dos dados. Na coleta documental, foram analisados os diários de classe do curso de Letras/Espanhol do IFB do período 2013-2016 (correspondente a um ciclo formativo) com a intenção de identificar quantidades e índices de reprovação em disciplinas e semestres letivos, representando o objetivo específico da pesquisa. Dos diários inferiuse que a reprovaçáo não manteve padrão preponderante. Na coleta de campo, foram realizadas entrevistas com os docentes do curso buscando compreender suas percepçóes em relaçáo à reprovação, o que constituiu o objetivo geral da investigaçáo. O corpus relativo à percepção dos professores foi submetido a um software de análise de dados textuais e apontou a existência de três categorias relativas às percepçóes docentes sobre reprovação: relação professor-estudante e sucesso acadêmico; motivadores da reprovação e sentido pedagógico; e reflexóes sobre a prática pedagógica quanto à reprovação. Destacase a influência do relacionamento interpessoal como fator promotor do sucesso e o uso 
de estratégias de enfrentamento da reprovação que se configuram como políticas a serem adotadas para permanência e êxito, tais como: atendimento individualizado; monitoria; iniciação à docência e pesquisa; bolsas de assistência estudantil; acompanhamento pedagógico; espaços de estudos e investimento em formaçáo docente.

Palavras-Chave: Educação. Êxito. Percepçóes Docentes. Reprovação.

Aвstract: The failure in higher education is a research object of this article. It was assumed that the teacher's perception about the failure influences the intentionality of pedagogical action and policies of permanence and success of students. The investigation was based on the quantitative-qualitative model for collecting, organizing and analyzing data. In the document collection, the class diaries of the IFB's Spanish course of the period 2013-2016 (which corresponds to a formative cycle) were analyzed with the intention of identifying quantities and indexes of failure in subjects and academic semesters, representing the specific objective the research. From the diaries it was inferred that failure did not maintain a preponderant pattern. In the field collection, interviews were carried out with the teachers of the course, seeking to understand their perceptions regarding failure, which constituted the general objective of the investigation. The corpus concerning the perception of teachers was submitted to a software of analysis of textual data and pointed out the existence of three categories regarding teachers' perceptions about failure: teacher-student relationship and academic success; motivators of failure and pedagogic sense; and reflections on the pedagogic practice as for failure. Stands out the influence of interpersonal relationships as a factor promoting success and the use of coping strategies that are defined as policies to be adopted for permanence and success, such as: individualized service; monitoring; introduction to teaching and research; student assistance grants; pedagogical monitoring; study spaces and investment in teacher education.

Keywords: Failure. Education. Success. Teaching Perceptions.

\section{Introdução}

Nos últimos anos, registrou-se no Brasil movimento de expansão do ensino superior que vai desde o aumento de vagas e cursos já existentes até a criação de novas unidades de ensino. É a partir do cenário de vultosos investimentos na educação pública que a Rede Federal de Educação Profissional, Científica e Tecnológica passa a ser questionada pela sociedade sobre a qualidade de seus serviços e a garantia de bons resultados, sendo este último aspecto diretamente associado ao número de pessoas certificadas para o exercício do trabalho. (BRASIL, 1997)

Ao longo do processo escolar, distintos fatores incidem sobre o quadro de diplomação das instituiçóes de ensino, dentre elas o fenôme- 
no chamado retenção por reprovação. $\mathrm{O}$ aumento da taxa de retenção, em especial na educação superior, representa não somente desperdício econômico relacionado ao aumento do gasto público, à carência de mão de obra especializada, à menor eficiência produtiva das organizaçôes (VASCONCELOS; SILVA, 2012); diz respeito também ao desperdício social que faz com que o sistema universitário se distancie de sua responsabilidade (DONOSO; SCHIEFELBEIN, 2007). Utilizada para indicar "o processo que resulta na permanência prolongada do estudante na universidade, levando a um atraso no período de integralização [...] do curso de graduação" (PEREIRA; BRASIL; CORASSA, 2014, p.2), a retenção no ensino superior, nesta pesquisa, é estudada a partir de uma visão ampliada do conceito, representando também a reprovação do estudante em disciplinas que compóem a matriz curricular.

Rissi e Marcondes (2011, p. 31) apontam que a reprovação é a "condição do aluno que reprovar por nota ou falta uma ou mais disciplinas; ou reprovar na disciplina essencial.” No curso de Letras/Espanhol do Instituto Federal de Brasília (IFB), contexto investigado, as disciplinas essenciais são aquelas que se apresentam como requisito para o prosseguimento da jornada acadêmica. Como são ofertadas anualmente, a reprovação assume caráter exponencial em relação ao tempo de permanência do estudante. Além disso, o Projeto Pedagógico do Curso (PPC) prevê um rígido esquema de pré-requisitos envolvendo componentes de Língua Espanhola, fazendo com que o aluno reprovado fique retido no desenvolvimento vertical do curso, o que favorece a evasão. Os baixos índices de conclusão de curso são também uma realidade. Na primeira turma a se formar no curso, o índice de diplomação foi de $10 \%$.

Para compreender melhor como o processo de formação profissional apresentou tais resultados, é preciso esforço sistemático e metódico que considere não somente a evasão como também outras variáveis. Por esse motivo, o presente estudo focaliza o fenômeno da retenção por reprovação a partir do contexto dos institutos federais, historicamente associados aos processos educativos que levam à geraçáo de trabalho e renda dos segmentos populares da sociedade.

Sobre essa especificidade, Noronha, Carvalho e Santos (2001, p. 15) destacam que "alunos que possuem empregos [...] são os que mais abandonam disciplinas e os que mais são reprovados, prolongando o curso. 
Tendo como principais motivos apontados a falta de tempo para estudar e a desmotivaçáo com a disciplina.” Lima (2006) apresenta nove pontos que considera as principais causas para a ocorrência da retenção: dificuldade acadêmica, adaptação, objetivos individuais, incertezas, comprometimento, fator financeiro, incongruência e isolamento. Tais causas estão centradas no estudante, porém, partimos do princípio de que a instituição deve se comprometer com políticas de permanência e êxito estudantil que perpassam outros aspectos motivadores da reprovaçáo. (PATTO, 1990)

\section{Material e métodos}

Para Flick (2009), a associação de abordagens em diferentes fases do processo de pesquisa pode se converter em importante passo para desvelar diversas facetas do objeto investigado. Diante disso, com o objetivo de explorar os índices e o perfil da reprovação no IFB, optou-se por abordagem quali-quantitativa, sendo a primeira etapa a de investigação documental, delineada pela análise de quantidades e índices derivados dos diários de classe produzidos dentro de um ciclo de formação (2013-2016), e a segunda representada pela análise da percepção docente quanto às possíveis causas da reprovação, a partir de entrevistas.

Reconhecido com o Conceito 5, a partir dos critérios estabelecidos pelo Sistema Nacional de Avaliação da Educação Superior, o curso de Licenciatura em Letras/Espanhol, nosso universo de pesquisa, é composto de 53 disciplinas, distribuídas em oito semestres.

Os dados relativos à reprovação foram organizados em tabelas, segundo a estrutura de núcleos formativos do PPC. Nelas constam as reprovaçóes por turma, que se referem ao ano de ingresso dos estudantes no curso, sendo: Turma 1, ingresso em 2013; Turma 2, em 2014 e assim por diante o que não impede que alunos de diferentes turmas cursem disciplinas juntos.

Para proceder à análise da percepção dos professores sobre a reprovação, foi elaborado roteiro de entrevista semiestruturada, composto de 11 questóes abertas. Os dados coletados foram submetidos ao software de análise de dados textuais Alceste - Análise Lexical Contextual de um Conjunto de Segmentos de Texto -, que aplica os princípios do méto- 
do de Análise de Conteúdo de maneira computadorizada (AZEVEDO; MIRANDA, 2012). O programa realiza cálculo de co-ocorrência lexical de um determinado segmento de texto como forma de distinguir classes de palavras que representam enunciados diversos sobre um objeto específico investigado (id.ib.). Em função da distribuição das palavras nos enunciados e nas associações estabelecidas entre elas é possível apreender o vocabulário mais característico desses discursos. De maneira geral, o Alceste procede metodologicamente seccionando o corpus em diferentes trechos, chamados de Unidades de Contexto Elementares (UCE), agrupando as UCE que compartilham o mesmo vocabulário e, dessa maneira, formando classes que representam distintos assuntos abordados no corpus.

É importante ressaltar que a interpretação semântica e os múltiplos sentidos verificados nas classes ou eixos foram apreendidos pelos pesquisadores por meio de leitura e interpretação exaustiva do relatório final gerado pelo programa.

\section{Discussão}

A Tabela 1 compreende os dados de reprovação nas disciplinas pertinentes à Formação Pedagógica e Instrumental, que tem como finalidade capacitar o estudante no campo do ensino, da investigação e da produção científica.

A reprovação foi crescente nos ciclos de oferta 2013/2015 e apresentou queda considerável em 2016. Infere-se que a queda possa estar relacionada à experiência do corpo docente ao ministrar a disciplina, uma vez que, para a maioria, essa foi a primeira experiência de docência na educação superior. A oferta de monitoria nas disciplinas com maiores índices de reprovação também pode colaborar para a redução da retenção, uma vez que a política de monitoria tem como objetivo "proporcionar reforço e atender aos alunos que estejam com dificuldade de aprendizagem.” (BRASÍLIA, 2014)

$\mathrm{Na}$ Tabela 2 estão relacionadas às disciplinas que tratam da formação do estudante como pesquisador e futuro docente da educação básica na área de Espanhol. Na disciplina Introdução à Língua Espanhola (ILE), a Turma 1 teve baixo índice de reprovaçáo; já a Turma 2 apresentou 55\% de alunos retidos. Nos anos seguintes, registra-se nova reduçáo da taxa de reprovação, o que leva a inferir que não há um padrão em relação a esse índice. 
Política de permanência e êxito na educação superior: perspectivas docentes sobre a reprovação escolar

\section{Tabela 1: Reprovação em Formação Pedagógica/Instrumental (\%)} (2013-2016)

\begin{tabular}{|c|c|c|c|c|c|c|c|c|}
\hline \multirow[t]{2}{*}{ Disciplina } & \multicolumn{8}{|c|}{ Semestre Letivo } \\
\hline & $1 / 2013$ & $2 / 2013$ & $1 / 2014$ & $2 / 2014$ & $1 / 2015$ & $2 / 2015$ & $1 / 2016$ & $2 / 2016$ \\
\hline Leitura e Produção de Textos I & 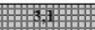 & & 22,5 & & 31,42 & & 19,51 & \\
\hline Cultura e Sociedade & 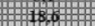 & & 33,33 & & 28,2 & & 20,45 & 20 \\
\hline $\begin{array}{l}\text { Leitura e Produção de Textos II } \\
\text { Fundamentos da Educacão }\end{array}$ & & ${ }^{3}$ & & $\begin{array}{c}14,28 \\
26\end{array}$ & & 22,72 & & 11.11 \\
\hline $\begin{array}{c}\text { Organização da Educação Brasileira } \\
\text { Metodologia Cientifica }\end{array}$ & & & $\frac{4}{8-4}$ & & $\begin{array}{l}11,11 \\
43,47\end{array}$ & & $\begin{array}{r}0,66 \\
15,78\end{array}$ & \\
\hline $\begin{array}{l}\text { Psicologia da Educação } \\
\text { Literatura Brasileira I }\end{array}$ & & & & Hes & & $\begin{array}{c}5,2 \\
0\end{array}$ & & $\frac{4,75}{7,14}$ \\
\hline Literatura Brasileira II & & & & & fo: & & 10,52 & \\
\hline $\begin{array}{l}\text { Planej. e Org. da Ação Pedagógica } \\
\text { Novas Tecnologias na Educação }\end{array}$ & & & & & & 18.18: & & 14,28 \\
\hline $\begin{array}{l}\text { Educação para a Diversidade } \\
\text { LIBRAS I } \\
\text { Projeto de Conclusão de Curso } \\
\text { Libras II } \\
\text { Trabalho de Conclusão de Curso }\end{array}$ & & & & & & & $\begin{array}{l}\frac{23}{2} \\
14=8 \\
12.5\end{array}$ & \\
\hline
\end{tabular}

Legenda:

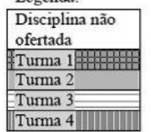

Fonte: Diários de classe do curso de Letras/Espanhol IFB

Tabela 2: Reprovação em Formação Técnico-Científica (\%) (2013-2016)

\begin{tabular}{l}
\hline \multicolumn{1}{c}{ Disciplina } \\
\hline
\end{tabular}

Fonte: Diário de classe do curso de Letras/Espanhol IFB 
Muitos estudantes não possuem proficiência no idioma por não ser requisito de ingresso no curso. No entanto, a proximidade tipológica entre língua materna e estrangeira cria o mito da facilidade, que atrai candidatos para essa licenciatura, criando paradoxo entre a familiaridade linguística, que deveria facilitar o aprendizado, e a dificuldade de transpor os conhecimentos do português para o espanhol. Sobre isso, Camorlinga (2010, p. 8) afirma que

[...] a vantagem inicial, quando da aprendizagem de uma língua cognata, nem sempre (aliás, raras vezes) culmina no domínio quase perfeito e rápido da língua visada. Muito pelo contrário, o mais provável é estacionar numa interlíngua, mais ou menos distante da meta. Facilmente a fossilização toma conta, inviabilizando qualquer progresso.

Pondera-se que o sentimento de incapacidade potencialmente gerado pela reprovaçáo nos primeiros semestres pode induzir a evasão ou a autoexclusão, já que ainda não houve tempo hábil para a criação do sentimento de pertencimento. $\mathrm{O}$ pertencimento a uma comunidade linguística implica na capacidade de vivenciar a língua e também de ser reconhecido por isso. Esse fenômeno não parte do sujeito, ele é produzido pela sociedade. Nesse sentido, a instituição de ensino assume papel central no processo de inclusão ou manutenção da exclusão social quando reconhece ou não as habilidades e competências desenvolvidas pelos aprendizes. (LEFFA, 2007)

A Tabela 3 apresenta os dados de reprovação em Prática de Ensino/ Estágio Supervisionado nas quais são desenvolvidas, in loco, atividades específicas do docente de Língua Espanhola. Em Prática de Ensino observase, nas Turmas 1 e 4, índice menor de reprovação do que nas Turmas 2 e 3. Em Estágio Supervisionado, observa-se queda da reprovação entre as Turmas 1 e 2 . 
Tabela 3: Reprovação em Formação Docente (\%) (2013-2016)

\begin{tabular}{|c|c|c|c|c|c|c|c|c|}
\hline \multirow[t]{2}{*}{ Disciplina } & \multicolumn{8}{|c|}{ Semestre Letivo } \\
\hline & $1 / 2013$ & $2 / 2013$ & $1 / 2014$ & $2 / 2014$ & $1 / 2015$ & $2 / 2015$ & $1 / 2016$ & $2 / 2016$ \\
\hline Prática de Ensino ( $\left(1^{\circ}\right.$ semestre $)$ & 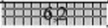 & & 35,71 & & 41,46 & & 19,56 & \\
\hline $\begin{array}{l}\text { Prática de Ensino }\left(2^{\circ} \text { semestre }\right) \\
\text { Estágio Supervisionado I }\end{array}$ & & 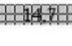 & & 18,18 & $4+4865$ & & 14,28 & |5|||| \\
\hline $\begin{array}{l}\text { Estágio Supervisionado II } \\
\text { Estágio Supervisionado III }\end{array}$ & & & & & & & 40 & 10 \\
\hline
\end{tabular}



Fonte: Diário de classe do curso de Letras/Espanhol IFB.

Tanto a disciplina de Prática de Ensino quanto a de Estágio Supervisionado estão diretamente relacionadas à aproximação do estudante a práxis educativa. Apesar de o estágio supervisionado ser significativo na formação, para os estudantes vivenciá-lo são necessários ajustes na rotina nem sempre viáveis a todos, tais como: atividades no contra turno das aulas, planejamento do ensino, confecção de materiais e enfrentamento do cotidiano escolar. Essas situaçóes podem levar o graduando a evadir da disciplina. Nesse caso, o professor precisa estar atento ao estudante, principalmente por meio da escuta sensível, de forma a intervir e promover o sucesso acadêmico. Infere-se que a queda nos índices de reprovação possa estar relacionada ao reconhecimento discente sobre as consequências da retenção por não integralização do curso e ao aumento da experiência docente na organização do trabalho pedagógico na licenciatura.

De modo geral, os dados indicam que a reprovação no curso não mantém padrão e oscila a depender do professor e da turma. Conclui-se ainda que essa inconstância possa estar relacionada à experiência do corpo docente e diretivo na educação superior; à cultura avaliativa e ao sentimento de pertencimento ao curso.

Destaca-se como limitador na análise a existência de possíveis falhas no registro acadêmico estudantil em relação ao sistema de matrícula em disciplinas, já que casos de trancamento ou aproveitamento de estudos podem constar como reprovação. Quanto a isso, sugere-se que a organização escolar seja esclarecida sobre a importância da disponibilização de infor- 
maçôes fidedignas como caminho a ser percorrido para a compreensão das causas da reprovação.

\section{A percepçáo dos professores acerca da reprovaçáo}

Os dados das entrevistas com os professores foram organizados em categorias denominadas classes e eixos. Num esforço de investigar seus conteúdos semânticos, foram atribuídos a elas nomes em função das formas reduzidas (palavras) e das UCE associadas. O Quadro 1 sintetiza as similitudes existentes no discurso docente sobre reprovação. Em seguida, apresenta-se a análise qualitativa dos pesquisadores sobre os conteúdos das falas. (Quadro 1)

A análise do corpus revelou forte aproximação entre as Classes 1/2 e entre as Classes 4/5, e fraca aproximação da Classe 3 com as demais. Constata-se a existência de eixos articuladores do discurso docente: Eixo A (Classes 1/2) revela a percepção dos professores em relação à influência do relacionamento interpessoal na promoção do sucesso do estudante e destaca a existência de estratégias que garantam as aprendizagens; Eixo B (Classes 4/5) traz reflexóes acerca dos motivadores da reprovação e seu sentido como estratégia pedagógica, e Eixo $\mathrm{C}$ (Classe 3) diz respeito à percepção dos professores em relação à prática docente e às estratégias pedagógicas adotadas para a minimização da reprovação.

\section{Eixo A - Relação professor-estudante quanto ao sucesso acadêmico}

O primeiro eixo fornecido pela análise das entrevistas realizadas com os professores 10, os quais receberam a identificação de Professor No, como forma para manter o sigilo sobre sua identidade, está organizado em duas classes e representa $52 \%$ da variância total do corpus. A maior parte do discurso investigado gira em torno da relação interpessoal entre professor-aluno e das estratégias adotadas para a aprendizagem.

As falas fortemente significativas para a análise indicam que os professores reconhecem que o relacionamento constituído em sala de 


\begin{tabular}{|c|c|c|c|c|}
\hline Classe 1 & Classe 2 & Classe 4 & Classe 5 & Classe 3 \\
\hline $\begin{array}{l}\text { Influência do } \\
\text { relacionamento } \\
\text { interpessoal no } \\
\text { sucesso do } \\
\text { estudante }\end{array}$ & $\begin{array}{c}\text { Estratégias } \\
\text { pedagógicas para } \\
\text { as aprendizagens }\end{array}$ & $\begin{array}{l}\text { Motivadores da } \\
\text { reprovação }\end{array}$ & $\begin{array}{l}\text { Reprovação } \\
\text { como estratégia } \\
\text { pedagógica }\end{array}$ & $\begin{array}{c}\text { Reflexões sobre } \\
\text { a prática } \\
\text { pedagógica }\end{array}$ \\
\hline $\begin{array}{l}\text { conversar } \\
\text { aprendizagem } \\
\text { observar } \\
\text { relacionamento } \\
\text { interpessoal } \\
\text { forma } \\
\text { avaliação } \\
\text { trabalhos } \\
\text { gosto } \\
\text { ensino } \\
\text { utilizar } \\
\text { sentido } \\
\text { trabalho } \\
\text { faltas } \\
\text { hora } \\
\text { diálogo } \\
\text { princípio }\end{array}$ & $\begin{array}{l}\text { atendimento } \\
\text { procurado } \\
\text { auxílio } \\
\text { dúvida } \\
\text { solicitado } \\
\text { campus } \\
\text { reflexão } \\
\text { ajudar } \\
\text { situação } \\
\text { necessidade } \\
\text { tentar } \\
\text { estudante } \\
\text { horário } \\
\text { coordenação } \\
\text { pedagógica } \\
\text { e-mail } \\
\text { monitor }\end{array}$ & $\begin{array}{c}\text { introdução } \\
\text { possa } \\
\text { partir } \\
\text { coisa } \\
\text { língua } \\
\text { conhecimento } \\
\text { principalmente } \\
\text { dia } \\
\text { entender } \\
\text { feita } \\
\text { gente } \\
\text { interesse } \\
\text { funciona } \\
\text { precisam } \\
\text { disciplina } \\
\text { aula }\end{array}$ & $\begin{array}{c}\text { conseguiram } \\
\text { matéria } \\
\text { reprovação } \\
\text { passar } \\
\text { segunda } \\
\text { ponto } \\
\text { considerar } \\
\text { processo } \\
\text { momento } \\
\text { problema } \\
\text { deixa } \\
\text { tentar } \\
\text { pensar } \\
\text { pessoa } \\
\text { cuidar } \\
\text { maturidade }\end{array}$ & $\begin{array}{l}\text { literatura } \\
\text { espanhol } \\
\text { ministrar } \\
\text { semestre } \\
\text { curso } \\
\text { terminar } \\
\text { alvo } \\
\text { muita } \\
\text { obras } \\
\text { período } \\
\text { media } \\
\text { final } \\
\text { tempo } \\
\text { retenção } \\
\text { perceber } \\
\text { língua } \\
\text { nível }\end{array}$ \\
\hline $38 \%$ das falas & $14 \%$ das falas & $12 \%$ das falas & $7 \%$ das falas & $29 \%$ das falas \\
\hline \multicolumn{2}{|c|}{$\begin{array}{l}\text { Relação professor-estudante quanto ao } \\
\text { sucesso acadêmico }\end{array}$} & \multicolumn{2}{|c|}{$\begin{array}{c}\text { Motivadores da reprovação e seu sentido } \\
\text { pedagógico }\end{array}$} & $\begin{array}{c}\text { Eixo C } \\
\mathbf{2 9 \%} \\
\text { Reflexões sobre } \\
\text { a prática } \\
\text { pedagógica } \\
\text { quanto à } \\
\text { reprovação }\end{array}$ \\
\hline
\end{tabular}

Fonte: Alceste - Relatório detalhado do Alceste: Resultados gerais. Junho (2017).

\section{Quadro 1: Síntese da análise da entrevista com professores}

aula pode interferir no desempenho estudantil, podendo ser um fator concorrente para o prolongamento do prazo de integralizaçáo do curso. Como exemplo, veja-se a fala da Professora 6: "[...] conversando com os alunos, muitos deles acabam desistindo em funçâo da forma como eles se relacionam com o professor, da forma como o professor o trata [...] conduz a aula."

Relaçóes dialógicas pressupóem respeito e empatia e são fundamentais na formação docente. Sobre isso, Freire (1996, p. 103) afirma que "o clima de respeito que nasce de relaçóes justas, sérias, humildes, generosas, 
em que a autoridade docente e as liberdades dos alunos se assumem eticamente, autentica o caráter formador do espaço pedagógico.” Para uma educação dialógica de perspectiva inclusiva é preciso assumir a diversidade das subjetividades e expectativas quanto a um projeto de vida. Grillo (2004) afirma que as biografias dos estudantes podem revelar disposiçóes e condiçôes específicas para a realização da trajetória acadêmica. Nesse sentido, os fragmentos a seguir indicam que os docentes consideram as experiências prévias pessoais e instrucionais dos estudantes como significativas para o percurso formativo:

[...] percebo que os alunos que abandonam as disciplinas não o fazem por questóes de aprendizagem, mas por motivos relacionados a dificuldades pessoais. (Professora 10)

[...] no momento em que o aluno pode tirar uma dúvida em sala de aula, em relação a um conteúdo que seria mais difícil, ele não o faz por uma vergonha por não saber. (Professor 3)

Como alternativas às dificuldades de aprendizado, professores buscam estratégias individuais ou institucionais (atendimento individual com professor, psicólogo, assistente social, pedagogo, monitor ou auxílios emergenciais oferecidos pela assistência estudantil) para o enfrentamento da reprovação, conforme sugerem os excertos a seguir:

[...] envio atividades extra como exercícios para aprimoramento dos conteúdos que tenham ficado com alguma lacuna. (Professor 9)

[...] sempre busquei esses recursos, sempre fui muito presente nessas questốes encaminhando para terapeuta, para os auxílios emergenciais. Sempre estive atenta a essas questóes sociais, psíquicas, de aprendizagem. (Professora 8)

[...] nas atividades avaliativas do semestre, algumas vezes, os alunos demandaram do monitor. (Professor 9)

[...] os alunos que tiveram melhor desempenho foram aqueles que apesar da dificuldade própria do componente me procuraram no atendimento ao aluno várias vezes, tiraram dúvidas. (Professor 5) 
A simples existência de recursos institucionais não basta para o enfrentamento da reprovação. Para melhor agir na realidade, é necessário diálogo que considere as necessidades específicas dos aprendizes de acordo com suas percepções. Para o fortalecimento das relaçóes interpessoais, Mosquera e Stobäus (2004) propóem aos professores, por vezes pouco dispostos a ouvir, o exercício de uma escuta sensível, ampla e capaz de considerar as subjetividades e realidades de cada aprendiz.

A preponderância desse eixo (52\%) no conjunto de dados analisados sugere que o relacionamento interpessoal e as estratégias alternativas individuais ou institucionais se apresentam como centrais no discurso docente sobre a minimização da reprovação.

\section{Eixo B - Motivadores da reprovaçáo e seu sentido pedagógico}

[...] ele compreenda essa necessidade porque a gente vê que eles têm imaturidade na cultura de estudar, ainda não firmou o que texto da licenciatura, exige-se explicitar sobre qual pressuposto de língua partem os formadores de futuros professores, uma vez que ele orientará as abordagens de ensino e também as expectativas de aprendizagem. Sobre isso, o fragmento de fala do Professor 1 sugere um conceito de língua pautado em aspectos meramente normativos, fundado sobre um conhecimento de caráter mnemônico: "[...] estão simplesmente para aprender a língua em si, mas para entender o funcionamento da língua, porque esse é um papel dele como futuro professor. Então ele tem que aprender as estruturas gramaticais."

Como motivadores da retenção por reprovação evidenciam-se na análise: o reduzido interesse, o hábito de estudo, o reconhecimento da rotina acadêmica na educaçáo superior e o excesso de faltas, conforme sugerem os seguintes excertos: gere que os professores reconhecem potenciais motivadores da reprovação e também indica que, em alguns casos, a retenção pode ser pedagogicamente benéfica à aprendizagem e à assimilação de conteúdo.

Para compreender a perspectiva docente sobre reprovação no con- 
é ser universitário, não entendem o que é isso [...] tem sim a falta de interesse deles. (Professor 8)

[...] frequência [...] ele estar na sala de aula, na aula, fazendo o que está proposto. (Professor 4)

A maturidade, a reflexão, a identificação com o curso e a carreira foram elementos que se articularam à percepção docente sobre a reprovação. Tais aspectos podem contribuir para a motivação do estudante, fazendo com que ele adote uma postura mais ou menos ativa em relaçáo à aprendizagem (FARIA, 2008). Identificar-se com o trabalho pedagógico e com a língua estrangeira são questóes centradas na ordem afetiva, fundamental para o aprendizado (OLIVEIRA, 2005). Mesmo ponderando sobre afeto e motivação no ensino superior, os excertos abaixo sugerem que a reprovação ainda assim pode assumir caráter positivo no processo de formação profissional:

[...] a retenção, às vezes, [...] é benéfica. $\mathrm{O}$ aluno naquele momento estava passando por um problema na vida ou é uma questáo de maturidade e não conseguiu. (Professor 5)

[...] momento para esse aluno pensar, parar, repensar se realmente as escolhas que estão sendo feitas são escolhas adequadas. (Professor 3)

Outro posicionamento discursivo significativo na análise trata do uso da reprovação enquanto estratégia de aprendizagem e oportunidade para a recuperação de conteúdos, evidenciado nos relatos a seguir:

[...] cursar uma disciplina duas vezes para, de fato, ter aquele conhecimento retido, claro e acessível pode ser benéfico. Até porque a gente está falando de disciplinas principalmente na área de línguas [...] que elas são cumulativas. (Professor 1) [...] não justifico uma retenção por conteúdo, por falta a gente realmente tem que reter [...] você tem que fazer uma recuperação. (Professor 6)

Os excertos anteriores mostram como os conteúdos são ressaltados discursivamente nas abordagens docentes, trazendo indícios sobre crenças 
e práticas pedagógicas que diretamente se relacionam à avaliação e, consequentemente, à reprovação estudantil. Na percepção dos professores, a avaliação, que possui funçôes didático-pedagógica, diagnóstica e de controle, fica reduzida a este último aspecto, sendo "utilizada para estabelecer, dentro do processo, quem já adquiriu os conteúdos e desenvolveu as habilidades e competências de uma determinada etapa do processo ensino-aprendizado, estando então apto a prosseguir." (RODRIGUES, 2012, p. 2)

A partir da análise desse eixo, verifica-se a importância da ampliação do sentido da avaliação no contexto da educação superior, pois, conforme apontam Faria (2008) e Oliveira (2005), é preciso considerar aspectos motivacionais e incluir a ordem afetiva na avaliação do desempenho, uma vez que a reprovação impacta diretamente na motivação e na autoestima estudantil, influenciando assim toda a trajetória escolar.

\section{Eixo C - Reflexóes sobre a prática pedagógica quanto à reprovaçáo}

O Eixo C representa $29 \%$ da variância total do corpus, o que sig-

[...] esse semestre eu refleti sobre minha prática, [...] talvez tenha sido o volume de obra que a gente tem que estudar no período, porque ele abarca o romantismo, o naturalismo, o realismo [...] (Professor 5)

[...] repensado após o término do curso todas essas questóes de metodologia, de estratégia de abordagens do próprio conteúdo [...] é muita coisa. (Professor 5)

Para o Professor 5 é possível que o excesso de trabalho imputado na faculdade possa levar os estudantes ao desgaste. Sendo assim, é preciso ampliar a noção de conteúdo, buscando identificar quais são de fato os conjuntos de conhecimentos, traduzidos em problemas, teorias, classifi- 
cações e categorias da área, que devem ser aprendidos (RODRIGUES, 2012). Pensar sobre conteúdos significa identificar precisamente o perfil de profissional que se quer formar na instituição, o que pode afastar geradores de esgotamento mental e promover o bom desempenho estudantil.

Para Tardif (2010), os professores têm lançado mão de um saber proveniente de sua experiência profissional, uma vez que é a partir de sua vivência pedagógica que selecionam o que lhes parece mais importante ser privilegiado em relação à formação do futuro professor. Nesse caso, infere-se que o reduzido tempo de experiência docente no ensino superior desfavoreça essa seleção.

Como exemplo de reflexão acerca da prática pedagógica adotada em relação aos procedimentos de recuperação, a fala do Professor 7 indica preocupaçáo sobre a efetividade do aprendizado de estudantes que continuaram mostrando dificuldades em disciplinas subsequentes, mesmo sendo aprovados por estratégias alternativas de avaliação:

[...] por outro lado, achei que também não resolveu os problemas porque as mesmas pessoas que foram "salvas", [...] e seguiram pra literatura $[\ldots]$ foram às mesmas pessoas que não alcançaram a média. (Professor 7)

Por fim, destaca-se no discurso docente a noção de autonomia em relação ao próprio percurso acadêmico. Conforme excertos a seguir, o sentimento de pertencimento traz consigo responsabilidade em relação à qualificação profissional.

[...] crucial para o aluno ver se realmente é o que ele quer [...], pois conforme os semestres vão passando eles vão se retendo mais ao curso. (Professor 1)

[...] eu ministrei disciplina para as alunas que estavam em processo de conclusão do curso [...] me pareceu que no final do curso a retenção diminuiu. (Professor 7)

Compreendido como sujeito adulto, responsável por sua própria vida, inclusive acadêmica, espera-se do futuro professor protagonismo na 
construção do conhecimento, autonomia intelectual, pensamento crítico e responsabilidade em sua trajetória formativa.

\section{Consideraçóes finais}

Como política pública, a educação profissional e tecnológica deve buscar o cumprimento de sua função social, qualificando cidadãos para atuação nos diversos setores da economia. Assim, o prolongamento do tempo de formaçấo para o exercício laboral pressupóe um entrave à concretização do papel dos institutos federais, aumentando o processo de acumulação de desvantagens sociais e econômicas do seu público-alvo.

A pesquisa aponta que, em termos gerais, a reprovação é um fenômeno complexo e multifacetado, que não pode ter suas causas reduzidas e localizadas unicamente no estudante. Nesse sentido, os professores, enquanto agentes de transformação, reconhecem a interface entre suas relações interpessoais, suas práticas docentes e as aprendizagens como aspectos concorrentes para a promoção do sucesso acadêmico. Para além da falta de interesse estudantil, é possível que o hábito de estudo mantenha relação com a organização do trabalho pedagógico e, também, com o desenvolvimento de competências anteriores ao ingresso no ensino superior. Essas competências dizem respeito tanto à formação promovida pela educação básica quanto à proficiência na língua estrangeira, que representam não um problema particular de cada estudante reprovado, mas o acúmulo histórico de desvantagens que se dão em uma estrutura de oportunidades. (DONOSO; SCHIEFELBEIN, 2007)

Destaca-se ainda que a organização do trabalho pedagógico é influenciada por um conceito de língua de caráter preponderantemente normativo, o que se relaciona a uma abordagem pedagógica fundada na hierarquização dos conteúdos e numa prática avaliativa como instrumento de controle. Sugere-se que os conteúdos passem a ser pensados em articulação com o perfil de profissional que se deseja formar na instituição, o que pode favorecer o desempenho estudantil.

As reflexóes docentes sobre a intencionalidade pedagógica bem como as estratégias individuais ou institucionais são fundamentais no enfrentamento da reprovação, mas tão importante quanto esses aspectos é o 
protagonismo estudantil no processo de aprendizagem e a auto reponsabilidade na construção da trajetória profissional. Sobre isso, observou-se alinhamento entre a redução das taxas de reprovação registrada nos diários de classe nos últimos semestres do curso e a percepção docente sobre a redução da reprovação ao final da licenciatura.

Os aspectos discutidos neste trabalho devem ser considerados pela instituição na formulação de políticas de permanência e êxito escolar, pois a reprovaçáo do estudante acarreta uma série de implicaçóes para a trajetória formativa, retardando a diplomação e a inserção no mercado de trabalho, como também gerando custo orçamental para a organização. Além disso, contribui para a queda na autoestima e diminuição do sentimento de pertencimento ao grupo, uma vez que o estudante não acompanha a turma com a qual iniciou os estudos, e aumenta a possibilidade de abandono do curso (BROPHY, 2006). Nesse caso, é preciso atentar para o papel da instituição de ensino como reprodutora da exclusão social, principalmente entre as classes populares. (LEFFA, 2007)

Franco (2008) propõe como desafio aos professores da educação superior: garantir uma formaçáo acadêmica fundada em perspectiva crítica e investigativa bem como repensar a organizaçáo dos cursos e as possíveis formas para melhorar o impacto da educação superior na sociedade. Para a superação de tais desafios, é indispensável a consideração da perspectiva docente na construção de qualquer que seja a chave de transformaçóes da educação. Por esse motivo, o presente estudo visou ao aprofundamento e à sistematização de conhecimento sobre o desempenho estudantil no que tange à retenção por reprovação, no curso de graduação em Letras-Espanhol, com a finalidade de subsidiar o processo de avaliaçáo institucional existente no IFB.

Como propostas de implementação de açôes que visem possibilitar a permanência e o êxito dos estudantes no processo de integralização do curso em tempo previsto, sugerem-se: 1) ampliação da compreensão das causas da reprovação, a partir da perspectiva de outros agentes, visando combatê-la; 2) investimento na formação continuada dos docentes; 3) criação de políticas de acompanhamento e orientação dos estudantes de modo sistemático; 4) ampliação dos programas de monitoria, iniciação à docência e à ciência; 5) incremento dos programas de auxílio financeiro para permanência do discente na IES e de estágios profissionais; e 6) desenvolvimento de propostas educacionais inclusivas. 


\section{Referências}

AZEVEDO, D. M. de; MIRANDA, F. A. N. Teoria das representaçóes sociais e ALCESTE: contribuições teórico-metodológicas na pesquisa qualitativa. Em: Revista Saúde \& Transformação Social, Florianópolis, v. 3, n. 4, p. 3-10, 2012. Disponível em: <http://www.redalyc.org/pdf/2653/265324588003.pdf>. Acesso em: 20 de nov. 2014.

BRASIL. Diplomação, retenção e evasão nos cursos de graduação em instituiçóes de ensino superior públicas. Relatório da Comissão Especial de Estudos sobre Evasão nas Universidades Públicas Brasileiras. Brasília: ANDIFES/ABRUEM/SESu/MEC, 1997.

BRASILIA. Política de assistência estudantil do Instituto Federal de Educação, Ciência e Tecnologia de Brasilia. Brasília: IFB, 2014.

BROPHY, J. Grade Repetition. Paris/Brussels: The International Institute for Educational Planning (IIEP) and The International Academy of Education (IAE), 2006. Disponível em: <http://unesdoc.unesco.org/images/0015/001520/152038e.pdf> Acesso em: $1^{\circ}$ de mai. de 2016.

CAMORLINGA, R. A distância da proximidade: A dificuldade de aprender uma língua fácil. Intercâmbio. Revista do Programa de Estudos Pós-Graduados em Linguística Aplicada e Estudos da Linguagem. ISSN 2237-759X, [S.1.], v. 6, out. 2010. ISSN 2237-759X. Disponível em: <https://revistas.pucsp.br/index.php/intercambio/ article/view/4098/2744>. Acesso em: 11 ago. 2017.

DONOSO, S; SCHIEFELBEIN, E. Análisis de los modelos explicativos de retención de estudiantes en la universidad: una visión desde la desigualdad social. Estudios Pedagógicos, vol. XXXIII, núm. 1, 2007, pp. 7-27. Universidad Austral de Chile. Valdivia, Chile.

FARIA, L. Motivação para a competência: O papel das concepções pessoais de inteligência no desempenho e no sucesso. Porto: Livpsic. 2008.

FLIK, U. Introdução à pesquisa qualitativa. Porto Alegre: Artmed, 2009.

FRANCO, A. de P. Ensino Superior no Brasil: cenário, avanços e contradiçôes. In: Jornal de politicas educacionais. $\mathrm{N}^{\circ} 4 \mid$ julho-dezembro de 2008 | pp. 53-63. Disponível em: <http://revistas.ufpr.br/jpe/article/view/15028/10076>. Acesso em 25 de mai. 2018.

FREIRE, P. Pedagogia da Autonomia. 18 ed. Rio de Janeiro: Paz e Terra, 1996.

GRILLO, M. O professor e a docência: o encontro com o aluno. In: ENRICONE, D. (org.) Ser professor. 4. ed. Porto Alegre: EDIPUCRS, 2004. p. 73-89.

LEFFA, V. J. Pra que estudar inglês, profe?: Auto-exclusão em língua-estrangeira. Claritas, Sáo Paulo, v. 13, n. 1, p. 47-65, maio 2007.

LIMA, V. M. Percepçóes de estudantes de primeiro periodo sobre o serviço educacional: análise empírica de uma IES privada na cidade do Rio de Janeiro. Rio de Janeiro: Faculdade Ibmec, 2006. 
MOSQUERA, J. J. M.; STOBÄUS, C. D. O professor, personalidade saudável e relaçóes interpessoais: por uma educaçâo da afetividade. In: ENRICONE, D. (org.). Ser professor. 4. ed. Porto Alegre: EDIPUCRS, 2004. p. 91-107.

NORONHA, B.N.; CARVALHO, B.M.; SANTOS, F.F.F. Perfil dos alunos evadidos da Faculdade de Economia, Administraçấo e Contabilidade campus Ribeirão Preto e avaliação do tempo de titulação dos alunos atualmente matriculados. Documento de Trabalho 01/2001, 57 p. NUPES - Núcleo de Pesquisa sobre Ensino Superior, Universidade de São Paulo. Disponível em: <http://sistema.semead.com.br/7semead/ paginas/artigos\%20recebidos/Ensino/ENS10_-_Avaliacao_da_evas\%E3o_e_ permanencia_prol.PDF>. Acesso em: 25 de mai. 2018.

OLIVEIRA, J. H. B. Psicologia da Educação: Aprendizagem - Aluno. Porto: Livpsic. 2005.

PATTO, M. H. S. A produção do fracasso escolar: histórias de submissão e rebeldia. São Paulo: T.A. Queiroz, 1990.

PEREIRA, A. S.; Carneiro, T. C. J. BRASIL, G. H.; CORASSA, M. A. de C. Perfil dos alunos retidos dos cursos de graduação presencial da Universidade Federal do Espírito Santo. Florianópolis, SC, 2014. Disponível em: < https://repositorio.ufsc.br/bitstream/ handle/123456789/131700/2014138.pdf?sequence=1> Acesso em: 7 de set. 2017.

RISSI, M. C.; MARCONDES, M. A. S. (org.). Estudo sobre a reprovação e retenção nos Cursos de Graduaçâo - 2009. Londrina: UEL, 2011. 163 p.: il. Disponível em: <http:// www.uel.br/proplan/LIVRO_CD_COMPLETO_Retencao_reprovacao.pdf $>$ Acesso em: 2 de mai. 2016.

RODRIGUES, H.W. Avaliação da aprendizagem nos cursos de Direito: novas e velhas possibilidades. In: Rodrigues, H.W.; Arruda Júnior, E. L. de. (Org.) Educação jurídica: temas contemporâneos. 2. ed. corr. Florianópolis: FUNJAB, 2012. 392p. Disponível em: <https://repositorio.ufsc.br/bitstream/handle/123456789/99622/ VD__FINAL_2a_ed_Educacao_Juridica_05-11-2012.pdf?sequence $=1$ \&isAllowed $=y>$. Acesso em: 11 de ago. 2017.

TARDIF, M. Saberes docentes e formaçẫo profissional. 11.ed. Petrópolis-RJ: Vozes, 2010. VASCONCELOS, A. L. F. de S.; SILVA, M. N. Uma investigação sobre os fatores contribuintes na retenção dos alunos no curso de ciências contábeis em uma IFES: um desafio à gestão universitária. Registro Contábil, v. 2, n. 3, p. 21-34, 2012.

Recebido em 20 set. 2017 / Aprovado em Io jan. 2019

Para referenciar este texto:

GONTIJO, S. B. F.; FORTUNATO, M. R.; YAMANAKA, J. H. C. Política de permanência e êxito na educação superior: perspectivas docentes sobre a reprovação escolar. EccoS - Revista Científica, São Paulo, n. 48, p. 43I-449. jan./mar. 2019.

Disponível em: $<$ https://doi.org/I0.5585/EccoS.n48.7845>. 
